\title{
FEDERALISMO ARGENTINO Y DESCENTRALIZACIÓN: SUS IMPLICANCIAS PARA LA FORMULACIÓN DE POLÍTICAS PÚBLICAS*
}

\author{
Leonardo Granato**
}

Fecha de recepción: 7 de marzo de 2015

Fecha de evaluación: 18 de mayo de 2015

Fecha de aprobación: 26 de mayo de 2015

Artículo de investigación

DOI:http://dx.doi.org/10.18359/dere.937

Forma de citación: Granato, L. (2015). Federalismo argentino y descentralización: sus implicancias para la formulación de políticas públicas. Revista Prolegómenos Derechos y Valores, 18, 36, 117-134. DOI:http://dx.doi.org/10.18359/dere.937

\section{Resumen}

Este artículo se propone analizar y discutir las especificidades del federalismo argentino y sus implicancias para la formulación de políticas públicas en el país. Se hará un recorrido histórico desde el periodo que siguió a la Revolución de Mayo de 1810, en el que Argentina se consolida como nación soberana, hasta la actualidad, describiendo las principales características del proceso de formación del Estado federal. Posteriormente, abordaremos lo que denominamos el "federalismo formal", en el que se incluirán los aspectos jurídicos, fiscales y de descentralización, y por último, el "federalismo político", cuyo propósito es brindar una interpretación de la dinámica y funcionamiento de la organización federal argentina.

\section{Palabras clave:}

Federalismo, Argentina, descentralización, políticas públicas.

\section{ARGENTINIAN FEDERALISM AND DECENTRALIZATION: ITS IMPLICATIONS IN THE FORMULATION OF PUBLIC POLICIES}

\section{Summary}

This paper aims to analyze and discuss the specifics of the Argentinian federalism and its implications in the formulation of public policies in the country. A historical overview will be

\footnotetext{
El presente artículo se enmarca en las actividades de posdoctorado desarrolladas por el autor en el ámbito del Grupo de Pesquisa "Estado, Administração Pública e Sociedade" (CNPq) -línea de investigación políticas públicas de inclusão social- del Programa de Pós-Graduação em Direito, así como del Centro Integrado em Estudos e Pesquisas de Políticas Públicas, ambos de la Universidade de Santa Cruz do Sul (UNISC), Brasil. El autor agradece el apoyo de la Coordenação de Aperfeiçoamento de Pessoal de Nível Superior (Capes), fundación del Ministerio de Educación de Brasil dedicada a la formación de recursos humanos de alto nivel en el país y en el exterior.

* Abogado por la Universidad de Belgrano (Argentina), Magíster en Derecho de la Integración Económica por la Universidad del Salvador (Argentina) en convenio con l'Université Paris 1 Panthéon-Sorbonne (Francia) y Doctor en Economía Política Internacional por la Universidade Federal do Rio de Janeiro (Brasil). Profesor adjunto de la Facultad de Derecho y Ciencias Políticas de la Universidad Abierta Interamericana (Argentina) y profesor de la Diplomatura Superior en Desarrollo, Política Públicas e Integración Regional de la Facultad Latinoamericana de Ciencias Sociales Sede Argentina. Actualmente, realiza su estancia posdoctoral en la UNISC, Brasil. Correo electrónico: granato@unisc.br.
} 
made starting at the aftermath of the May Revolution of 1810, when Argentina consolidated itself as a sovereign nation, to the present, describing the main features of the formation of the federal state. Later, we will discuss what we call the "formal federalism", including legal, fiscal and decentralization issues, and finally, the "political federalism", whose purpose is to provide an interpretation of the dynamics and operation of the Argentinian federal organization.

\title{
Keywords:
}

Federalism, Argentina, decentralization, public policies.

\section{FEDERALISMO ARGENTINO E DESCENTRALIZAÇÃO: AS SUAS IMPLICAÇÕES PARA A FORMULAÇÃO DE POLÍTICAS PÚBLICAS}

\begin{abstract}
Resumo
Este artigo tem por objetivo analisar e discutir as especificidades do federalismo argentino $e$ as suas implicações para a formulação de políticas públicas no país. Primeiramente, faremos um perpassar histórico a partir da Revolução de Maio de 1810, que consolida a Argentina como uma nação soberana, até ao presente, descrevendo as principais características da formação do Estado federal. Em seguida, abordaremos o chamado "federalismo formal", em que estarão presentes as questões jurídicas, fiscais e de descentralização e, finalmente, o "federalismo político", cujo objetivo é proporcionar uma compreensão da dinâmica e do funcionamento da organização federal argentina.
\end{abstract}

\section{Palavras-chave:}

Federalismo, Argentina, descentralização, políticas públicas.

\section{A. Introducción}

El federalismo ${ }^{1}$ entendido como un proceso dinámico y con numerosas fórmulas posibles de configuración reviste una complejidad que durante largo tiempo ha ocupado la atención de intelectuales, académicos y analistas del mundo jurídico, del poder político y de la organización estatal en general. Con el objeto de estudiar y discutir las especificidades del federalismo argentino y sus implicancias para el formulación de políticas públicas en el país, vista su importancia como herramienta estratégica para el desarrollo armónico de la nación así como mecanismo de integración nacional, nos proponemos, inicial-

1 Del latín fæedus, que significa "contrato", "acuerdo", "pacto", entre otras acepciones en esta misma línea. mente, hacer un recorrido histórico desde el periodo que siguió a la Revolución de Mayo de 1810, en el que Argentina se consolida como país soberano, hasta la actualidad, describiendo las principales características del proceso de formación del Estado federal en un contexto de graves y persistentes conflictos entre las unidades federativas argentinas, las provincias.

El propio devenir histórico nos permitirá concluir que si bien existen normas que trazan el "reparto" de competencias o atribuciones entre las diferentes instancias de gobierno del Estado nacional argentino, las relaciones de esas instancias no son simples ni lineales, sino que, por el contrario, están determinadas por factores que van más allá del propio andamiaje jurídico constitucional. 
En razón de lo anterior, abordaremos, en segundo lugar, lo que denominamos como "federalismo formal", en el que se incluirán los aspectos jurídicos y fiscales del sistema federal en la Argentina, y en tercer lugar, el "federalismo político", cuyo propósito es brindar una interpretación de la dinámica y funcionamiento de la organización federal. En ese marco, se buscará analizar cómo se organizan los actores políticos, la influencia del régimen electoral, el papel que desempeñan los gobiernos provinciales (y en menor medida, los municipales) en materia de implementación de políticas públicas, así como en la provisión de bienes y servicios públicos, y la significativa centralidad del gobierno federal en el plano fiscal.

Sobre la base de que la organización federal argentina es resultado de propósitos deliberados y objetivos alcanzados por parte de actores estratégicos con intereses diversos, aportaremos evidencias para demostrar que la Argentina es una federación descentralizada en la que los gobiernos provinciales son políticamente autónomos, pero financieramente dependientes, que conviven con un presidencialismo fuerte, con una alta concentración geográfica de recursos productivos y con amplias desigualdades interprovinciales.

Con el presente artículo, producto de nuestra participación e intervención en un encuentro que buscó abordar los federalismos argentino y brasileño en perspectiva comparada ${ }^{2}$, esperamos contribuir con los estudios de federalismo y descentralización en perspectiva comparada y con las investigaciones en materia de políticas públicas.

\section{B. Descripción del trabajo}

A los efectos de cumplir con el objetivo propuesto, primero veremos los aspectos históricos y políticos del federalismo argentino, en el que discutiremos el papel de las provincias en el proceso constituyente de la República Argentina,

2 Este evento, en forma de coloquio, tuvo lugar en la sede del Observatório dos Consórcios Públicos e do Federalismo (OCPF) en São Paulo (Brasil) en agosto de 2014. repasando brevemente sus diversos intereses, así como los conflictos emergentes de los mismos, y cómo ello dio lugar a diferentes acuerdos que desembocaron finalmente, en el establecimiento del sistema federal consagrado en la Constitución Nacional de 1853.

Después daremos cuenta de las especificidades jurídicas y económico-financieras, desde la óptica de los nuevos temas incorporados por la reforma constitucional de 1994, y que tuvo entre sus premisas más destacadas, el fortalecimiento del proceso de descentralización política, administrativa y fiscal del país ${ }^{3}$. Luego, valiéndonos de los conceptos preliminares, estudiaremos el funcionamiento del "federalismo político" a través de la dinámica relacional establecida entre sus actores provinciales y el gobierno central y sus implicancias en la formulación de políticas públicas. Por último, formularemos algunas conclusiones, identificando posibles desafíos para el sistema federal argentino.

\section{Aspectos históricos del federalismo en Argentina}

Si bien se señalan múltiples causas originarias del federalismo argentino por parte de prominentes juristas e historiadores, en líneas generales, la gran mayoría coincide en que las raíces históricas de este fenómeno deben buscarse en el régimen municipal español mediante los "cabildos", que dieron lugar a las "provincias" (vocablo para identificar a las unidades federativas argentinas), y a la ausencia de una soberanía nacional, que causó las soberanías locales (Hernández, 2010; Martiré, 2010).

Ahora bien, más allá de aparecer como consecuencia de las particulares características de la conquista y la colonización hispánica en América, veremos que el federalismo fue la forma de Estado que se eligió para resolver los

\footnotetext{
Entendemos por descentralización al traspaso del poder y toma de decisión del Estado central hacia otras estructuras de gobierno, como las provincias y municipios, reforzándose así el carácter democrático del Estado y el principio de participación.
} 
graves conflictos interprovinciales ${ }^{4}$ producto de la gran heterogeneidad social y política interna, así como de los distintos niveles de desarrollo, herencia de las notables diferencias y desigualdades existentes en el propio virreinato del Río de la Plata creado en 1778.

Al producirse la Revolución de Mayo de 1810 y decretarse la libertad como paso previo a la independencia y la organización definitiva del país, nos encontramos con un movimiento político-institucional gestado en Buenos Aires y que luego se desplegó en todo el territorio hispánico en América. Por convicción o por la fuerza, casi todas las ciudades mayores y menores que constituían el mapa geográfico-político de la etapa colonial, y que luego se constituirían en provincias, fueron adhiriendo al primer gobierno que se había despojado de la corona española, llamado "Provincias Unidas del Río de la Plata".

En el periodo que siguió a mayo de 1810 y hasta 1820, las Provincias Unidas del Río de la Plata iniciaron su existencia como país soberano, la sostuvieron exitosamente por medio de una prolongada guerra de independencia y declararon su independencia. Pero también, durante este periodo, producto de los conflictos políticos y económicos (tales como el control del único puerto internacional del país y de sus ingresos de aduana, las políticas comerciales y la forma de organización institucional centralizada o descentralizada), las Provincias Unidas fracasaron en darse un gobierno y una Constitución.

Conforme sus diferentes intereses, las provincias independientes y soberanas, se dividían entre aquellas que querían la libre navegación de los ríos y las que preferían un control monopólico del puerto; entre aquellas que deseaban nacionalizar los recursos aduaneros y las que pretendían un control provincial de sus propios ingresos de aduana ${ }^{5}$; entre las que se orientaban a un pro-

$4 \quad$ Para el desarrollo de este apartado nos inspiramos en Saguir (2007).

5 En referencia a la navegación de los ríos, mientras que las provincias del interior apoyaban políticas de libre navegación y la instalación de nuevos puertos a lo largo teccionismo comercial y las que propiciaban el libre cambio; entre las que pretendían procesos centralizadores del poder en el territorio y las que querían descentralizarlo porque entendían que una forma de Estado menos concentrada era más conveniente para el desarrollo del país ${ }^{6}$.

Tales intereses influyeron en el modo en el que las provincias concibieron los posibles esquemas de organización nacional. Desde un punto de vista analítico, son dos los esquemas organizacionales que se pueden considerar para explicar los escenarios posibles que enfrentaron los actores: la secesión o separación y la unión.

La secesión consistía en que las distintas provincias pudiesen separarse unas de otras y estructurarse por su propia cuenta como entidades políticas autónomas e independientes. Esta alternativa hubiera llevado, eventualmente, a la completa división del nuevo territorio independiente. En la primera década revolucionaria, una solución institucional de este tipo se presentaba inviable porque las chances de las provincias de derrotar a España y asegurar que la revolución fuera exitosa eran menores si se escindían.

Una segunda solución a los conflictos interprovinciales era la unión, a través de la agrupación de todas las provincias dentro de un diseño institucional particular que regulara sus interacciones, decisiones y conflictos. La unión presentaba, desde el punto de vista de las preferencias centralizadora o descentralizadora de los dirigentes revolucionarios, dos diseños institucionales posibles: el unitario y el federal.

En el diseño unitario, un ente central reunía todo el poder soberano y las provincias no existían

de sus costas, la provincia de Buenos Aires deseaba mantener el control del puerto así como de los recursos de aduana y de la regulación de la navegación fluvial, los cuales emergían del antiguo privilegio monopólico otorgado por el virreinato del Río de la Plata.

6 En cuanto a las políticas comerciales, Buenos Aires quería abrir el comercio a todos los productos y a todos los países del mundo, mientras que las provincias del interior se oponían a ello, siendo partidarias de imponer ciertos límites a la introducción de bienes extranjeros. 
como entidades autónomas sino que dependían enteramente de la voluntad de la nación. A diferencia del anterior, el diseño federal permitía a las provincias tener cierto tipo de independencia en sus propios asuntos, y al mismo tiempo, crear un gobierno de alcance nacional que pudiera decidir sobre cuestiones comunes. Dentro del esquema federal podían encontrarse a su vez dos formas posibles: la confederación y la federación.

Mientras que la confederación implicaba una asociación donde los estados retenían todo poder soberano y el ente central dependía por completo de sus voluntades; la federación suponía estados que concentraban cierta soberanía dentro de su propia esfera, con un ente central con capacidad $e$ influencia propia sobre cuestiones comunes a todas las partes.

Con miras a comprender la lógica del funcionamiento del Estado federal en general, nos valemos de la definición de Lijphart (2000, p. 178), para quien el "federalismo es una organización política en la que las actividades del gobierno están divididas entre los gobiernos regionales y el gobierno central de modo que cada tipo de gobierno tiene ciertas actividades en las que toma decisiones finales", así como de lo expresado por Rodden (2005, p. 17) en el sentido de que el federalismo no es una simple distribución de autoridad entre gobiernos, sino "um processo -estruturado por um conjunto de instituições-por meio do qual a autoridade é distribuída e redistribuída". Si bien los dirigentes políticos de la época no podían establecer con exactitud los efectos distributivos de uno y otro modelo, la previsión de algunos efectos en sentido amplio, hacía preferir uno más que el otro. Discutamos, a continuación, cuáles eran los argumentos.

El diseño unitario aparecía como la solución institucional óptima para las preferencias políticas de la élite revolucionaria porteña. En el corto plazo, un sistema unitario presentaba una estructura más eficiente para responder a los requerimientos de la guerra de independencia. En el largo plazo, y siempre y cuando su élite revolucionaria lograra el control del Estado central, esta alternativa ofrecía mejores instrumentos para un control hegemónico de la organización política del país y el consecuente beneficio económico de Buenos Aires. No obstante, la alternativa unitaria también demandaría altos costos para Buenos Aires, dado que sería esa provincia la que debería efectuar la contribución más importante a la administración y a la atención fiscal de todo el país.

En lo que respecta al diseño federal de la nación, la élite porteña entendía que el mismo sería viable solo si Buenos Aires conseguía mantener cierta independencia política, así como también el control de sus políticas comerciales y recursos económicos. La condición para ello era que los porteños controlaran políticamente los mecanismos nacionales de representación y de decisión, manteniendo su influencia (hegemonía) sobre las otras provincias. Por su parte, las provincias del interior se inclinaban por el sistema federal, dado que se esperaba que este les asegurase un grado sustantivo de autonomía local y la posibilidad de participar del proceso de toma de decisiones en el ámbito nacional, entre otros beneficios.

Entre 1810 y 1830 existieron varios gobiernos centrales que, desde Buenos Aires, intentaron permanecer, pero no lo lograron: la Primera Junta (1810) fue sucedida por la Junta Grande y por la Junta Conservadora (1811); del Segundo Triunvirato (1812-1814) se pasó al Directorio (1814-1820), y por último, la Presidencia de 1826-1827. Esta suerte de "Estado provisorio permanente", reflejaba la tensión y conflicto entre las provincias y el carácter fuertemente centralizador de Buenos Aires que impedía toda alternativa de conjugar la independencia y la soberanía de las provincias con la unificación.

De esta forma, el panorama rioplatense mostraba una suerte de postal de varias provincias autónomas relacionadas entre sí, a través de más de cien acuerdos de integración, conciliación y pacificación ${ }^{7}$, que frente al poder amenazante de Buenos Aires no atinaban conciliar sus intereses

7 Por ejemplo, el Tratado del Pilar de 1820 o el del Cuadrilátero de 1822. 
en una propuesta constitucional única en la que todas las provincias estuviesen representadas.

En este contexto, merece una mención especial el Pacto Federal de 1831, que se transformaría en la piedra fundamental de la Confederación Argentina. Este pacto fue suscripto por los llamados "trece ranchos": Santa Fe, Corrientes, Salta, Jujuy, Santiago del Estero, Catamarca, Córdoba, La Rioja, San Juan, San Luis, Mendoza y las antiguas Repúblicas de Tucumán y de Entre Ríos. Una de las cláusulas del citado pacto, la que preveía el llamado a un Congreso Nacional, fue percibida por Buenos Aires como una amenaza constante a sus intereses, derivando en 1834, en la disolución del cuerpo representativo nacional. Así, además de la posición privilegiada de Buenos Aires en el Río de la Plata que le garantizaba el control del comercio, de los recursos aduaneros y de la navegación interior, en el gobierno de Juan Manuel de Rosas, esta provincia centralizaría también el manejo de los asuntos militares y de las relaciones exteriores de las provincias, hasta la caída del gobernador en $1852^{9}$.

Las provincias sabían que el único modo de contrabalancear el poder de Buenos Aires era incorporándola a una organización nacional, para lo cual debían sancionar una Constitución. Así, en 1853, con el objetivo de instituir la unión nacional, afianzar la justicia y consolidar la paz interior, se acordó la reunión de un Congreso Constituyente a reunirse en Santa $\mathrm{Fe}$, aunque sin la participación de la provincia de Buenos Aires. Sobre la base de una supuesta fortaleza institucional y económica, las provincias del interior sancionaron la Constitución de la Confederación Argentina sin la concurrencia de Buenos Aires.

Los convencionales de Santa Fe de 1853 sancionaron la Ley Suprema teniendo como precedente el modelo norteamericano de $1787^{10}$,

8 Forma peyorativa de los porteños para referirse a las provincias del interior.

9 Para ampliar informaciones sobre el periodo 1810-1853, véase Chiaramonte (1993).

10 No debemos dejar de aclarar que, a diferencia de los Estados Unidos, en donde el sistema federal consistió en que estableció una República presidencialista como forma de gobierno y el federalismo como forma de Estado, además de otro antecedente directo $e$ inmediato, el célebre libro Bases y puntos de partida para la organización política de la República Argentina (Valparaíso, 1852) del padre del derecho público argentino, el prócer tucumano Juan Bautista Alberdi.

De conformidad con los principios de la federación norteamericana, nuestro Estado comportó la coexistencia de distintos órdenes estatales y gubernamentales, el federal y los provinciales, con una distribución de competencias que otorga al primero solo las facultades delegadas en modo expreso o implícito, mientras que a las provincias les corresponden las facultades residuales, además de su propia autonomía en lo institucional (poder constituyente), político, financiero y administrativo.

De cualquier manera, cabe aclarar que en esta primera versión normativa del federalismo de 1853 se consagró un modelo más "centralizado" que el estadounidense, con notoria influencia del pensamiento de Alberdi, quien consideraba que la forma de Estado más adecuada para los países evolucionados era el régimen unitario. Así, se cristalizó una fórmula "mixta" de "federalismo unitario", que sin desconocer la potestad de las provincias de elegir sus propios gobernantes y reglar sus instituciones particulares, aceptaría la existencia de un poder central o suficientemente poderoso como para imponer la legislación de fondo y conducir la vida nacional e internacional sin trabas ni dificultades.

Una Constitución donde las competencias acordadas al gobierno central resultaban más im-

un proceso de centralización de funciones y competencias de los estados locales preexistentes hacia el Estado federal, la Argentina adoptó el federalismo más bien como una fórmula superadora de los antagonismos y luchas civiles entre unitarios y federales, siendo que los integrantes de este último grupo no eran propiamente "federalistas" en el sentido del modelo norteamericano, sino "independentistas" que propugnaban una confederación de estados soberanos cuyo principal fundamento era la oposición a la provincia de Buenos Aires. 
portantes que las reservadas a las provincias: de este modo el gobierno central contaba con las facultades de revisar las constituciones provinciales, aprobar los tratados interprovinciales y de sancionar la legislación de fondo por parte del Congreso Nacional; intervenir los territorios provinciales por propia decisión y, por último, la competencia de los tribunales federales para resolver los conflictos interprovinciales.

Las provincias no pudieron subsistir sin Buenos Aires y forzaron su reunificación a través de la Batalla de Cepeda en 1859, cuya pérdida obligó a Buenos Aires a suscribir el Pacto de San José de Flores por medio del cual pasaría a integrar la Confederación Argentina. En 1860, se llevó a cabo una trascendental revisión y complementación del texto de 1853 por la que, entre otras cosas, se dispuso que se utilizara la denominación "Constitución de la Nación Argentina", y se suprimió el mecanismo de control político del Congreso Nacional sobre las provincias con la intención de afirmar una mayor descentralización del poder, y por tanto de fortalecimiento de las autoridades provinciales, en desmedro de las amplias competencias que se habían reconocido al gobierno federal, atenuándose la influencia alberdiana.

En 1862 tuvo lugar la Batalla de Pavón, donde los porteños, al mando del general Mitre, vencieron y proyectaron su influencia sobre el resto de las provincias del interior. De esta forma, Mitre se transformó en presidente de la nación unificada, y los tres poderes se trasladaron a la ciudad de Buenos Aires, aunque el gobierno nacional carecía de autoridad administrativa sobre la ciudad, que formaba parte de la provincia de Buenos Aires. La necesidad de "federalizar" la ciudad, y con ello, el puerto y los ingresos aduaneros, produjo una serie de enfrentamientos que culminaron con la derrota de la provincia de Buenos Aires y la consecuente federalización de la ciudad de Buenos Aires, convirtiéndose en capital federal del país.

En líneas generales, en el periodo histórico que va desde 1862 hasta el regreso a la democracia en 1983, el poder central intentó avanzar sobre los poderes provinciales. La principal herramienta para pretender corromper al sistema federal fue la disposición constitucional que faculta al gobierno nacional para intervenir las administraciones provinciales ${ }^{11}$. Esta fórmula ha sido interpretada de manera tal que las provincias han estado expuestas a una permanente intervención del poder central, abandonando sus orientaciones tradicionales y la defensa de sus intereses permanentes, a fin de conseguir ventajas momentáneas e individuales, al "amparo" de las "instrucciones" recibidas por parte del gobierno nacional.

El federalismo ha sufrido además, históricamente, los avatares de la vida política argentina. No solo la amenaza de la intervención federal, los mayores recursos económico-financieros del gobierno central y el fuerte presidencialismo desempeñan, de cierto modo, un rol "desfederalizante", sino también los recurrentes gobiernos de facto (militares) que se sucedieron desde 1930 hasta 1976 y que no solo terminaron con los poderes federales, eliminando las autonomías provinciales, sino también con los gobiernos democráticos en todas las provincias, convirtiendo a los gobernadores en una suerte de agentes directos del gobierno central.

Por último, el sistema de la coparticipación, creado en 1935, que tiene por objeto coordinar la distribución del producido de los tributos impuestos por el Estado central, tampoco ha contribuido al afianzamiento del sistema federal, toda vez que los porcentajes de la distribución primaria siempre favorecieron sensiblemente al Estado nacional en desmedro de las provincias ${ }^{12}$.

Ahora bien, a partir del restablecimiento democrático de 1983, y durante el gobierno del presidente Raúl Alfonsín (1983-1989), se produjo un ejercicio de las autonomías provinciales y municipales de honda incidencia en la modernización de nuestro

11 Hasta ahora, este instituto de carácter extraordinario no ha sido reglamentado.

12 Por ejemplo, en 1935, la distribución primaria establecía que la nación se quedaba con $82 \%$ de los recursos y las provincias con el 17,5\%. 
derecho público, que encuentra sustento en las siguientes cuestiones: a) en este periodo se dio la plena vigencia de la Constitución y de sus instituciones republicanas, federales y democráticas; b) no hubo intervenciones federales; c) se impulsó la sanción de la ley 23.512 de traslado de la capital federal de la ciudad de Buenos Aires a las ciudades de Viedma y Guardia Mitre (provincia de Río Negro) y Carmen de Patagones (provincia de Buenos Aires); d) se impulsó la sanción de la ley 23.548 de coparticipación impositiva, que ocasionó por primera vez, una distribución primaria donde la mayor parte de los recursos correspondía a las provincias y no al gobierno central; y e) se promovió la reforma constitucional de $1994^{13}$.

La mencionada reforma constitucional, que tuvo como base el llamado "Pacto de Olivos", acordado por los entonces líderes de los dos principales partidos políticos del país (Carlos Menem por el Partido Justicialista y Raúl Alfonsín por la Unión Cívica Radical), tuvo como una de sus grandes premisas el fortalecimiento de la descentralización del poder en el territorio, y en esa dirección abordaremos en el punto que sigue las reglas y normas formales e "informales" del federalismo argentino.

Tal como vimos hasta el momento, las instituciones argentinas son el producto o el efecto de conflictos y competencias entre actores guiados por sus intereses. En ese sentido, consideramos de gran relevancia explicar no solo la "forma" del federalismo sino también su funcionamiento desde el punto de vista de los actores sujetos de la relación federal.
13 La Constitución de 1853/60 rige hoy con las reformas de 1866, 1898, 1957 y la más reciente operada en 1994. Sobre esta última, véase Sabsay (1999).

\section{El federalismo formal: aspectos jurídicos y fiscales}

\section{El sistema federal en la Constitución Argentina}

Simplificando al extremo la cuestión, el federalismo argentino es, según Bazán (2013), una combinación de dos fuerzas: una centrípeta y la otra centrífuga. La primera, que va de la periferia hacia el centro, supone la existencia de una unidad en el Estado nacional argentino, que es soberano; mientras que la segunda, que va del centro a la periferia, implica la descentralización que permite la existencia de una pluralidad de provincias que tienen el carácter de autónomas. Precisamente, el esquema federal pugna por establecer la unidad dentro de la pluralidad, a través de los principios de autonomía y de participación (Bazán, 2013).

El artículo $1^{\circ}$ de la Constitución establece que la nación argentina adopta para su gobierno la forma representativa, republicana y federal. Las dos primeras son formas de gobierno, mientras que la tercera es una forma de Estado que supone un vínculo entre el poder y el territorio en el cual aquel se descentraliza políticamente con base física o geográfica. En este contexto, los tres poderes (ejecutivo, legislativo y judicial) se controlan unos a otros y contribuyen a garantizar esa descentralización del poder.

Así mismo, el texto supremo consagra tres órdenes de gobierno en la federación argentina: a) el gobierno federal (arts. 44 al 120, de la segunda parte); b) los gobiernos de provincia (arts. $121 \mathrm{al}$ 128), aquí se incluye al gobierno autónomo de la ciudad de Buenos Aires, con una naturaleza de "ciudad-Estado" distinta de las provincias y los municipios (art. 129) y, c) los gobiernos municipales autónomos en el orden institucional, político, administrativo, económico y financiero (arts. 5 y 123).

Siguiendo el hilo descriptivo que propone Bidart Campos (2006), las relaciones típicamente formales en la estructura federal argentina son de 
subordinación, en razón de la cual los ordenamientos locales deben ajustarse al ordenamiento federal; de participación, por la que se concede cierto espacio de colaboración de las provincias en las decisiones del gobierno federal, a través de la Cámara de Senadores; y de coordinación, que delimita las competencias federales y provinciales mediante una distribución o un reparto.

En función de este "reparto", podemos efectuar de acuerdo con el criterio del citado jurista, el siguiente esquema de "distribución de competencias" (Bidart Campos, 2006) ${ }^{14}$, que tiene como soporte la máxima consagrada en la norma fundamental que decreta que las provincias tienen poderes conservados e ilimitados, y que la administración federal ejercita los poderes delegados en forma expresa o implícita, siendo, por tanto, poderes limitados: competencias conservadas por las provincias ${ }^{15}$; competencias delegadas al gobierno federal ${ }^{16}$; competencias concurrentes entre los dos órdenes gubernamentales ${ }^{17}$; competencias excepcionales de las provincias ${ }^{18}$; competencias excepcionales del gobierno federal ${ }^{19}$; competencias compartidas entre el Estado federal y las provincias, es decir, que requieren una doble decisión integradora ${ }^{20} ; \mathrm{y}$ competencias prohibidas a toda instancia gubernamental ${ }^{21}$.

En función de lo dicho, resta aclarar que las provincias no pueden invadir los ámbitos de competencia federal ni derogar las fuentes normativas federales con un nivel jerárquico superior a las provinciales. Ahora bien, tal como hemos visto, el federalismo argentino plasmado en la Constitución de 1853/60 tiene como principales

14 Véase también Gelli (2011).

15 Por ejemplo, dictar sus propias constituciones y normas procesales.

16 Por ejemplo, dictar el Estado de sitio.

17 Por ejemplo, establecer los impuestos indirectos internos.

18 Por ejemplo, dictar los códigos de fondo mientras no los sancione el Congreso Nacional.

19 Por ejemplo, crear impuestos directos y solo por tiempo determinado.

20 Por ejemplo, fijar la capital de la República.

21 La concesión de facultades extraordinarias o la suma del poder público a quien ejerza el correspondiente poder ejecutivo, presidente, gobernador, intendente. protagonistas al Estado nacional y a las provin$\operatorname{cias}^{22}$, quedando excluidos los municipios ${ }^{23}$. Luego de la reforma de 1994, el artículo 123 clarificó la condición de los mismos en tanto sujetos participantes de la relación federal, a través de la provincia de la que forman parte, consagrándose el principio de subsidiariedad tan directamente vinculado y relacionado con el de descentralización del poder ${ }^{24}$.

El artículo 123 declara que "cada provincia dicta su propia constitución, [...] asegurando la autonomía municipal y reglando su alcance y contenido en el orden institucional, político, administrativo y financiero". Los órdenes de autonomía previstos en la norma en mención suponen: el institucional, la potestad de los municipios de dictarse su propia Carta Fundamental por medio de una convención convocada al efecto; el político, la capacidad de nominar a sus autoridades y regirse por ellas; el administrativo, la autorización para gestionar y organizar los intereses, servicios y obras locales; y el económico-financiero, la habilitación para diseñar su modelo rentístico, administrar su presupuesto, recursos propios y la inversión de los mismos.

22 Como ya comentamos, las provincias argentinas preexistieron a la nación. No las veinticuatro que hoy conforman el Estado argentino (contando a la ciudad de Buenos Aires), sino las catorce que existían al momento de estructurarla. Luego se fueron agregando otras y "provincializándose" territorios nacionales hasta llegar al número actual (el último en provincializarse fue el territorio de Tierra del Fuego, Antártida e Islas del Atlántico Sur en 1991).

23 Según datos de la Asociación Argentina de Presupuesto y Administración Financiera Pública (ASAP), en 2010 se registró un total de 2.269 gobiernos locales en la Argentina. Véase cuadro VIII.1 Cantidad de gobiernos locales, por categoría, 2010, en: http://www.asap.org. ar/informes-fiscales/estadisticas-fiscales/

24 Para Boisier (2004) la descentralización representa la aplicación del principio de subsidiariedad, de acuerdo con el cual cada organización social es competente para intervenir sobre su propio ámbito (funcional o territorial), transfiriendo "hacia arriba" solo aquello que el bien común o la tecnología establezca como responsabilidad del ente mayor. En función de lo expuesto, entendemos al principio de subsidiariedad como aquel que tiene por objeto garantizar que las decisiones se tomen lo más cerca posible del ciudadano. 
Como se advierte, de tan amplias atribuciones reconocidas a los municipios emergen límites al gobierno provincial, e indirectamente, al gobierno nacional. De cualquier manera, la autonomía no debe vulnerar la distribución de competencias entre el Estado federal y las provincias en ninguna materia en general, ni en materia tributaria en particular.

La República Argentina es un Estado federal constituido por veintitrés provincias y una ciudad autónoma. Cada provincia tiene competencias legislativas en los términos que establecen sus respectivas constituciones, en las que de forma expresa manifiestan su adhesión a la República. El poder ejecutivo de cada provincia lo ejerce el gobernador electo por los habitantes de la provincia; $y$ entre sus atribuciones se encuentra la de hacer cumplir la Constitución y las leyes de la nación, de ahí que la Constitución Nacional se refiera a ellos como agentes naturales del gobierno federal.

El poder legislativo provincial es ejercido por la correspondiente legislatura provincial que puede ser unicameral o bicameral. Cada provincia se divide en "departamentos", salvo en el caso de la provincia de Buenos Aires donde reciben la denominación de "partidos". Cada departamento está a su vez dividido en distritos y estos en localidades. Las localidades se clasifican en lo administrativo, principalmente en función del número de habitantes. La naturaleza, composición y competencias del gobierno de cada localidad depende de su rango, fijándose en las diferentes constituciones los criterios de clasificación y las formas de gobierno.

Las localidades que superan un cierto número de habitantes, o por declararlo una ley provincial, se designan como "municipios" estando gobernadas por una municipalidad o municipio cuya rama ejecutiva la ejerce el intendente (o viceintendente) elegido por sufragio universal directo, y cuya rama legislativa, con potestad para la sanción de ordenanzas municipales, es ejercida por un concejo deliberante, siendo el número de concejales función de la cifra de habitantes del municipio del último censo realizado.
El resto de localidades que cumplan unos requisitos mínimos (existencia de casco urbano, por ejemplo) podrán ser administradas por una comisión de fomento que constará de un presidente y varios vocales. En ambos casos se establecerán los límites del ejido municipal que será gobernado por la municipalidad o la comisión. Esta estructura administrativa es dinámica y tiene el propósito de colaborar en la descentralización del Estado.

Ahora bien, ¿̇cuál es la situación actual del régimen municipal en la Argentina? De las veintitrés constituciones provinciales, solamente tres (Mendoza, Santa Fe y Buenos Aires) aún no reconocen la autonomía institucional de sus municipios, es decir, aún no acatan el mandato constitucional previsto en el artículo 123 citado, frente a las veinte restantes que sí consagran la autonomía municipal en sus cuatro niveles (institucional, político, administrativo y económico-financiero) con los matices propios y particulares de cada ordenamiento territorial.

Por otra parte, de las veinte provincias que reconocen la autonomía municipal, cuatro de ellas (Neuquén, Salta, Chubut y Tucumán) condicionan el poder constituyente local al contralor del poder legislativo provincial; otras establecen que la organización del régimen municipal será determinado por leyes provinciales (por ejemplo, San Luis, Formosa, Santiago del Estero, Chaco, Jujuy, etc.) y solo se les dará la capacidad de dictarse su propia carta orgánica a aquellos municipios con mayor número de habitantes; en otros casos, son las propias constituciones provinciales las que precisan los requisitos o condiciones básicas que deberán contener las cartas municipales que se sancionen (por ejemplo, Misiones).

Finalmente, existen otras dos cuestiones que vulneran el principio de autonomía municipal: una de ellas se observa en la mayoría de los textos provinciales en cuanto ponen a cargo de los superiores tribunales provinciales la resolución de conflictos municipales, y la otra es el instrumento de intervención municipal (en analogía a la intervención provincial por parte del 
gobierno nacional), también previsto en varios textos constitucionales provinciales.

\section{La prestación de servicios públicos y la creación de regiones}

Dos de los varios temas que fueron objeto de la reforma constitucional de 1994 íntimamente relacionados con el principio de descentralización gubernamental, son el de los servicios públicos y el de creación de regiones para el desarrollo.

En primer lugar, la materia que se vincula con los servicios públicos es de especial atención para el ordenamiento constitucional nacional, provincial y municipal, porque hace a la esencia misma del Estado, que es asegurar el bienestar general ${ }^{25}$. El principio general que fija nuestra Constitución es que las provincias tienen competencia para determinar sus servicios públicos en la medida que son autónomas, que se trata de una facultad no delegada, y porque tienen plenas facultades para darse sus propias instituciones locales $y$ regirse por ellas.

De igual modo, la provincia tiene la facultad de dictar las normas del marco regulatorio de los servicios provinciales y de crear los organismos de control que (a su vez) decreten las normas reglamentarias en los aspectos específicos del servicio que tenga por objeto cada caso. Sobre las fuentes de recursos y las posibilidades de financiamiento de las provincias haremos referencia más adelante.

Por último, para precisar la competencia municipal en materia de servicios públicos, estamos en la obligación de analizar el texto constitucional provincial que sirve de referencia en cada caso, y por ello, la regla aquí es que la competencia es provincial ${ }^{26}$. Ahora bien, no podemos dejar

25 Para ampliar, véase Granato y Oddone (2006).

26 Dentro de una gran heterogeneidad, las principales acciones y políticas que habitualmente lleva a cabo un municipio se enlazan con la provisión de los servicios de recolección de residuos, suministro de agua potable y energía eléctrica, la limpieza y mantenimiento de calles y caminos vecinales, alumbrado público, riego, mante- de aclarar que gracias a su privilegiada inmediatez en el trato con la realidad comunitaria que le permite detectar con mayor precisión las necesidades públicas, el municipio se convierte en el responsable principal y más directo de los servicios públicos.

El segundo de los temas de este apartado se conecta con la potestad que se otorga a las provincias de crear regiones para el desarrollo económico y social y de establecer órganos con facultades para el cumplimiento de sus objetivos. Tal premisa debe leerse en línea con el artículo 125 parte inicial, que permite a las provincias la celebración de tratados parciales para fines de administración de justicia, de intereses económicos y trabajos de utilidad común, con conocimiento del Congreso, y con el artículo 126 que les proscribe celebrar tratados parciales de carácter político.

De tal normativa surge que la región no es una nueva instancia política en el sistema institucional argentino, sino que podría entenderse como una herramienta de "oxigenación federal", en términos de vehículo descentralizador. La creación de regiones es una facultad de las provincias, convirtiéndose en un instrumento que procura grados más avanzados de cohesión social y territorial, y de desarrollo económico equilibrado ${ }^{27}$.

\section{Federalismo fiscal: la ley-convenio de coparticipación impositiva}

Es en el campo fiscal donde la relación naciónprovincias adquiere sus aspectos más conflictivos. Como ya comentamos, el actual régimen de coparticipación federal de impuestos se inauguró en la década de 1930, cuando, por una ley del Congreso se dispuso que parte de los impuestos

nimiento de los cementerios, etc. No obstante, también hay provincias, como la de Buenos Aires, en la que algunos municipios financian escuelas y establecimientos de salud que permanecen en la órbita municipal.

27 En la actualidad, existen en el país cuatro regiones formalmente constituidas: Patagonia, Nuevo Cuyo, Centro y Norte Grande Argentino. Para ampliar este tema, véase Farah, Granato y Oddone (2010). 
indirectos nacionales (la gran porción de la carga tributaria) se distribuyera entre las provincias. El monto y los términos de esas transferencias variaron con el tiempo, pero continúan siendo fuente permanente de disputas entre la nación y las provincias, dada la fuerte concentración de fondos en el tesoro nacional. A pesar del mandato de la reforma constitucional de 1994, aún no se logró consensuar y sancionar una ley, convirtiéndose en uno de los grandes temas que, hoy por hoy, persisten sin resolución en la Argentina ${ }^{28}$.

Durante el gobierno de Néstor Kirchner, en 2004, el poder ejecutivo impulsó la aprobación de un "Acuerdo para la creación del Sistema de Coordinación de Relaciones Fiscales Intergubernamentales" que, según su artículo $1^{\circ}$ estaría conformado por un nuevo régimen de coparticipación federal, la adopción de principios de responsabilidad fiscal y un Consejo de Coordinación Fiscal y Financiero.

Esta propuesta del gobierno nacional revestía dos grandes problemas: por un lado, no cumplía con el mandato de la Constitución Nacional, dado que la misma manda a aprobar una ley-convenio, $y$ esto se trataba de un simple "acuerdo" y, por otro, tampoco estaban fijados los criterios objetivos de reparto señalados en las bases constitucionales de la coparticipación, lo que perjudicaba a las provincias y a los municipios, al mantenerse los mismos criterios en cuanto a la masa coparticipable, distribución primaria (entre la nación y las provincias) y secundaria (entre estas y la ciudad de Buenos Aires entre sí) y asignaciones específicas vigentes a 2004.

En esta materia se aplica desde la última década la misma política centralista de los años noventa (decenio en el que el gobierno del presidente Menem disminuyó el porcentaje de la distribución primaria que se había reconocido a las provincias durante el gobierno de Alfonsín), y se intenta introducir un nuevo fondo para aumentar la

28 Para ampliar, véase Hernández (2008) y Dalla Via (2011). discrecionalidad del gobierno central respecto de la transferencia de fondos a las provincias, incrementando así aún más la subordinación económica de estas últimas respecto del gobierno nacional. Si bien varias provincias objetaron el proyecto de acuerdo del presidente Kirchner, ello no impidió la continuidad del mismo, y la consecuente dilación de la sanción de un régimen de coparticipación conforme con los principios $y$ lineamientos constitucionales.

En la actual coyuntura, el régimen de coparticipación ocasiona ineficiencia (un elevado índice de evasión), no hay control eficaz sobre el ingreso y el gasto, y se genera ambigüedad sobre la propiedad de los recursos tributarios. La nación gira fondos a las provincias sin sujetarse a reglas objetivas, sino que, por el contrario, esas transferencias suelen ser el resultado del arbitrio con el que el gobierno nacional, según De Riz (2008), suele distribuir "premios y castigos".

Los procedimientos de la administración presupuestaria que confieren un amplio margen de maniobra a la figura presidencial para decidir los gastos en las provincias, resultan ser una herramienta con la que el presidente consigue sus apoyos políticos, desatendiendo las pautas de objetividad, equidad y solidaridad en el reparto formalmente establecidas en la Constitución.

Es imprescindible sancionar la ley-convenio de coparticipación impositiva que determine una masa coparticipable que no sea disminuida por la elevada cantidad de asignaciones específicas hoy vigentes. Así mismo, debería precisarse la distribución primaria y secundaria con base en los criterios que establece la Constitución Nacional. Estos criterios son los de equidad, solidaridad, desarrollo igualitario, calidad de vida e igualdad de oportunidades en todo el territorio nacional.

En este sentido, un mayor reconocimiento de la participación de las provincias (que necesariamente debe repercutir en la coparticipación a los municipios) hará relativamente más simple la discusión sobre la distribución secundaria, donde se advierten las disputas más frecuentes 
entre las provincias más grandes y desarrolladas y las pequeñas y atrasadas. Producto de esta situación es un país de grandes diferencias y desequilibrios de producto bruto o de ingreso per cápita ${ }^{29}$.

En suma, el sistema impositivo debe ser consensuado y coparticipado, debe tratarse de un sistema instrumentado por la nación junto con las provincias, donde ellas participen en la imposición, porque esta en definitiva es parte de las provincias. Además, la distribución debería efectuarse en relación directa con las competencias, servicios y funciones que cada provincia tenga, contemplando criterios objetivos de reparto, que será equitativo, solidario y dará prioridad al logro de un grado equivalente de desarrollo, calidad de vida e igualdad de oportunidades en todo el territorio nacional.

\section{E. El federalismo político: implicancias en la formulación de políticas públicas}

Ya abordamos los aspectos jurídicos y fiscales del federalismo "formal". Ahora el propósito de este apartado es brindar una interpretación sobre el federalismo político y su funcionamiento, en el que, además, nos valdremos de los conceptos hasta aquí expuestos. Para hacer esta interpretación sobre el funcionamiento del federalismo político, nos soportaremos en el estudio de Leiras (2013) quien parte de dos afirmaciones: la primera de ellas es que la Argentina es una federación política y administrativamente descentralizada con alta concentración geográfica de los recursos productivos y amplias desigualdades interprovinciales; y la segunda, que los gobiernos provinciales argentinos son, en general, débiles y dependientes desde el punto de vista financiero, pero fuertes y autónomos desde el punto de vista político ${ }^{30}$.

29 Los índices de desarrollo humano prueban la disparidad que se registra. Véase Artana, Cristini, Moskovits, Bermúdez y Focanti (2010).

30 Para comprender las lógicas de interacción política que se generan en Argentina véase también Falleti, González y Lardone (2013).
Lo que se busca afirmar en el estudio de Leiras (2013) es que, en la Argentina, la descentralización coexiste con la concentración de recursos (desigualdad interprovincial ${ }^{31}$ ) y que la autonomía política provincial coexiste con la subordinación financiera. Estas combinaciones son factibles y no le quitan en nada el carácter de "federal" a la forma del Estado argentino, sino que, por el contrario, estas "contradicciones" son el resultado del funcionamiento de las instituciones federales en una determinada coyuntura socioeconómica del país, así como de la trayectoria histórica que hemos tratado en este trabajo.

De esta forma, el carácter descentralizado del federalismo argentino y la concentración de recursos suscitan una dinámica general en la que las políticas públicas en la escala nacional se apoyan en coaliciones interprovinciales que los presidentes construyen transfiriendo a los líderes provinciales recursos financieros a cambio de respaldo electoral y legislativo (Leiras, 2013). En el razonamiento de Leiras subyace una forma muy interesante de concebir el federalismo en términos de "conjunto de reglas" para tomar decisiones, y no en términos de "resultados".

31 Los principales factores que contribuyen a esta "desigualdad interprovincial" son las diferencias en materia de capacidades productivas y de distribución poblacional. Para tener una idea un poco más acabada de estas disparidades conviene resaltar que tan solo cuatro provincias (Buenos Aires, Córdoba, Santa Fe y Mendoza) más la ciudad autónoma de Buenos Aires generan casi el $80 \%$ del PBI, mientras que ocho (Corrientes, Chaco, Formosa, La Rioja, Santiago del Estero, Jujuy, Misiones y San Juan) generan tan solo un 7 \% del mismo. Esta situación pone en evidencia que, a pesar de la recuperación observada en los últimos años por las economías regionales, persisten serias dificultades en muchas provincias del país para incrementar, de un modo genuino, su capacidad para ejecutar estrategias de desarrollo endógeno. Por otra parte, con respecto a la distribución demográfica, el $60 \%$ de la población se concentra en la ciudad autónoma de Buenos Aires y en las provincias de Buenos Aires, Córdoba y Santa Fe. Le siguen Mendoza y Tucumán, y luego Chaco, Corrientes, Entre Ríos, Misiones y Salta, con aproximadamente un millón de habitantes cada una. Sobre este tema, véase Asensio (2012). 
Si bien podría considerarse de cierta forma "contradictorio" que en una federación los recursos estén geográficamente concentrados o que las desigualdades interprovinciales sean notorias, en rigor, estas cuestiones son un "resultado" esperable tanto en las federaciones como en cualquier otro régimen territorial de gobierno. Así mismo, la coexistencia de asimetrías o desigualdades entre las unidades federativas es muy frecuente, no tanto porque el federalismo las produzca o acentúe esta desigualdad, sino porque la propia historia demuestra que son aquellas naciones con grandes desigualdades y desequilibrios territoriales las que han adoptado formas de Estado federales como forma de unión o integración. Ese es el caso, de hecho, de Argentina.

Las federaciones pueden, en ocasiones, promover el desarrollo económico y la igualdad, pero debemos ser conscientes de que ese no es el propósito fundamental de la adopción de reglas federales. Las federaciones se forman para integrar territorialmente (o mantener integradas) naciones económica y socialmente heterogéneas cuyas élites locales tienen intereses parcialmente compatibles pero también contradictorios. A cambio, las federaciones obtienen mayor extensión territorial y peso demográfico, con todas las ventajas políticas y económicas asociadas a la gran escala.

En suma, que la población y las capacidades productivas se concentren en la ciudad de Buenos Aires y en el territorio de la pampa húmeda, y que la desigualdad interprovincial de los ingresos y de las condiciones de vida de los habitantes sean pronunciadas, puede derivar en que Argentina sea catalogado como un país "mal integrado" o "socialmente injusto", pero en ningún caso puede llevar a quitarle su carácter de "federal".

Expresadas estas consideraciones iniciales sobre la naturaleza federal del sistema argentino, retomemos la afirmación central de Leiras: corresponde calificar a la Argentina como una federación política y administrativamente descentralizada. Según este autor, una federación está políticamente descentralizada cuando la dimensión territorial es en especial relevante para la formación de mayorías legislativas y coaliciones políticas de gobierno a escala nacional; y los gobiernos territoriales están autorizados para ejercer completamente o compartir con el nivel central numerosas y salientes funciones de gobierno (Leiras, 2013).

En referencia al primer argumento, las instituciones de representación política del país ofrecen un amplio espacio para la manifestación y la influencia de los actores y los intereses provinciales sobre las decisiones de carácter nacional. La sobrerrepresentación de los distritos pequeños y el bicameralismo simétrico ${ }^{32}$ (ambas cámaras, de diputados y senadores, pueden iniciar legislación o enmendar la legislación aprobada por la otra cámara) contribuyen al carácter descentralizado del federalismo argentino: cualquier mayoría legislativa que se forme en el Congreso argentino necesita del apoyo de representantes de los distritos menores ${ }^{33}$.

Con relación al segundo punto que sostiene el autor, podemos expresar que los gobiernos provinciales tienen un papel crucial en materia de implementación de políticas públicas, así como en la provisión de bienes y servicios públicos. Ello deriva de la participación de las provincias en el gasto público total ${ }^{34}$. Según datos brindados por

32 En Argentina, el Congreso Nacional adopta el sistema bicameral justamente para poder dar lugar a la representación de las provincias en el Senado y la representación popular a través de la Cámara de Diputados. En esta última, se establece un piso mínimo de cinco diputados por provincia para que las provincias más despobladas tengan representación en la Cámara baja.

33 Ello se explica por el contraste entre la distribución interprovincial de la representación en ambas cámaras y la distribución interprovincial de la población. Por ejemplo, el tamaño de la población de la provincia más poblada, Buenos Aires, es 123 veces más grande que el de la menos poblada, Tierra del Fuego. Sin embargo, la delegación bonaerense en la Cámara de Diputados es solamente 14 veces más grande que la fueguina. La diferencia entre la distribución de la población y la de las bancas hace que las provincias más grandes estén subrepresentadas y las más pequeñas, sobrerrepresentadas. En el caso del Senado la discrepancia se acentúa puesto que allí todas las provincias tienen tres senadores.

34 Rubros que incluyen: funcionamiento del Estado, social, servicios económicos y servicios de la deuda pública. Cabe 
la ASAP, mientras que en 2004 el gasto público total ejecutado por los gobiernos provinciales representó un $9,95 \%$ del PBI contra 11,98\% por parte del gobierno nacional, en 2009 el gasto público ejecutado por las provincias representó un $13,40 \%$ contra poco más del $19 \%$ del gobierno central ${ }^{35}$.

Por otra parte, debemos destacar la alta influencia de las provincias en la provisión de bienes de alta visibilidad pública dado que los mismos ejecutan, casi todo el gasto en rubros de gasto público social, cuyos porcentajes más elevados responden a educación, cultura, ciencia y técnica; le sigue salud, previsión social, promoción y asistencia social, y vivienda.

En líneas generales, podríamos sostener que las provincias participan intensamente y con amplios márgenes de autonomía en la decisión y en la implementación de políticas públicas en sus territorios; no así los municipios, los cuales deberán buscar diferentes canales de articulación

aclarar que la incidencia de los gobiernos provinciales en la ejecución del gasto público ha crecido, impulsada tanto por las políticas de descentralización como por una expansión general del sector público.

35 Véase cuadros III.1.2.2 (Gasto público del gobierno nacional - en porcentaje PBI) y 3.1.3.b (Gasto público de los gobiernos provinciales y GCABA - en porcentaje PBI) en http://www.asap.org.ar/informes-fiscales/ estadisticas-fiscales/ Es importante aclarar que los procesos de descentralización del gasto operados desde el nivel central hacia las administraciones provinciales no se acompañaron con medidas similares de estas últimas hacia los municipios, excepto los casos de las provincias de Buenos Aires y Córdoba. En consecuencia, el gasto público municipal representa un porcentaje muy bajo del gasto total ejecutado por las administraciones subnacionales (provincias y municipios). En el ámbito municipal, además de los recursos provenientes de los regímenes de coparticipación entre provincias y municipios, existen los no tributarios (tasas, derechos y contribuciones). Ahora bien, un nuevo elemento en el financiamiento de los municipios está dado por las transferencias naciónmunicipios, que facilita la construcción de la autonomía municipal. Según datos del Observatorio de Políticas Públicas del Cuerpo de Administradores Gubernamentales de la Jefatura de Gabinete de Ministros las transferencias nación-municipios en millones de pesos pasaron de 20,6 para el año 1995 a 1.486,4 para 2006. con el gobierno provincial ${ }^{36}$. Dada la organización territorial del régimen electoral, y la distribución de facultades entre las cámaras del Congreso Nacional, la agregación de intereses en la escala provincial resulta decisiva en la conformación de mayorías para respaldar las decisiones de escala nacional ${ }^{37}$.

No obstante, desde la óptica financiera, los gobiernos provinciales parecen ser, en general,

36 La relación entre los municipios y sus provincias se formaliza a través del poder legislativo provincial, sea este unicameral o bicameral, en donde los legisladores representan a "conjuntos municipales". Pero si bien los legisladores provinciales representan, por lo general, a varios municipios, es muy común observar que esta representación se ejerce por "turnos" y cada legislador, en su turno, se focaliza más en los intereses de su ciudad o distrito, dejando al resto rezagado. Algunas leyes provinciales prevén la conformación de "consejos" e invitan a participar a los municipios. Esta instancia de articulación permite la puesta en marcha de determinadas políticas públicas de interés compartido. Empero, las relaciones más comunes entre un gobernador y los jefes comunales de su provincia resulta ser bastante asimétrica, excepto en aquellos casos de municipios con economías robustas o significativos caudales de votos.

37 Uno de los ámbitos de convergencia más destacados entre la nación y las provincias en los que se abordan temas de interés común con miras a la formulación e implementación de políticas públicas conjuntas son los "consejos federales". La denominación de cada uno de ellos dará cuenta de la política sectorial sobre la que trabajan, podrán asumir diferentes estructuras y modalidades de funcionamiento. Conforme con las reglas del sistema federal argentino, la participación de las provincias en estos consejos es voluntaria. Si bien durante la década del noventa creció la cantidad de este tipo de espacios de concertación y articulación, lo cierto es que esta práctica tiene más de medio siglo de existencia. Los primeros consejos se relacionan con las políticas de cuño desarrollista del periodo 1958-1962. El Consejo Vial Federal y el Consejo Federal de Catastro son de 1958, el Consejo Federal de Inversiones es de 1959 y el de Energía Eléctrica de 1960. El Directorio de consejos federales de la República Argentina está disponible en: http://www.sgp.gov.ar/contenidos/cofefup/documentos/docs/Directorio_Consejos_Federales. pdf Por su parte, si bien desde el punto de vista formal, la relación nación-municipios está dada a través de la Secretaría de Asuntos Municipales del Ministerio del Interior, en la práctica nada limita a los intendentes y demás autoridades locales para entablar vínculos con las autoridades nacionales a los fines de conseguir programas y proyectos que apoyen y fortalezcan su gestión. 
débiles y dependientes del gobierno federal. El argumento central que justifica esta formulación es simple: si bien como vimos, el gasto público está descentralizado, los ingresos tributarios están "concentrados" en el nivel federal de gobierno. Como consecuencia de ello, la dependencia de los gobiernos provinciales respecto de las transferencias del gobierno nacional es, para la mayoría de las provincias, muy alta y tiende a crecer (Leiras, 2013).

Según datos de la ASAP, en 2013 la incidencia de los ingresos recaudados por los gobiernos provinciales sobre el total de la recaudación tributaria se mantuvo en niveles cercanos al $16 \%$ contra el $83,3 \%$ del gobierno nacional ${ }^{38}$. La diferencia entre lo que los gobiernos provinciales recaudan y lo que gastan se financia, en general, con transferencias del gobierno central, las que están sujetas a distinto grado de discrecionalidad tanto en la asignación de los fondos por parte del ejecutivo como en su aplicación y utilización por parte de las provincias. En este sentido, el régimen de coparticipación federal es solo un componente de un esquema de reparto sumamente complejo tanto por sus reglas, como por lo imprevisible de sus resultados. Otro modo de financiar los desequilibrios fiscales de las provincias es la emisión de deuda, que, conforme los mecanismos de reestructuración vigentes, también las coloca en situación de dependencia respecto del gobierno nacional.

Ningún gobierno provincial se financia hoy en Argentina con los ingresos que recauda de modo independiente ${ }^{39}$. En este sentido, según la ASAP, entre 2004 y 2013 el porcentaje del PBI de transferencias a las provincias de recursos de origen nacional creció del 5,27 al 6,64\% . De esta

38 Véase cuadro II.6.5 (Recursos tributarios del sector público argentino - en porcentaje del PBI. 2013) en http://www. asap.org.ar/informes-fiscales/estadisticas-fiscales/

39 Las provincias recaudan mediante imposiciones exclusivamente provinciales que por lo general gravan la propiedad, la circulación y transferencia de automotores, la emisión de sellos y la transmisión gratuita de bienes.

40 Véase cuadro III.8.2 (Transferencia a provincias de recursos de origen nacional por concepto - en porcentaje forma, y siguiendo la dinámica observada por Leiras (2013), si bien los gobernadores tienen el control sobre los recursos políticos de sus provincias (la actividad de las máquinas electorales y el voto de los diputados y senadores), también necesitan los recursos que el Estado nacional les puede ofrecer ${ }^{41}$.

Por ende, gran parte de la literatura crítica coincide en el hecho de que las estadísticas muestran que, históricamente, las transferencias del gobierno nacional no han tenido como propósito redistribuir los recursos a favor de las provincias con menor nivel de ingreso, sino que, más bien, han estado vinculadas con el rendimiento de los votos en el Congreso. Puesto que las provincias pequeñas tienen la misma cantidad de votos que las "grandes" en el Senado, y pesan más que su volumen demográfico en la Cámara de Diputados, los recursos financieros nacionales ${ }^{42}$ suelen dirigirse a ellas con más frecuencia, y en mayor magnitud que al resto.

El resultado de esta dinámica es que el Estado nacional termina concentrando recursos en las provincias de menor tamaño poblacional, y como no hay correlación entre la riqueza y el tamaño de las provincias, el efecto redistributivo de las transferencias acaba siendo, en algún sentido, "neutro", sin atender los pautas de equidad y solidaridad establecidas en la Constitución Nacional. Por ello uno puede imaginarse una coalición ganadora que esté compuesta por provincias con ingresos superiores al promedio, $y$ por otras pobres y pequeñas, y entender por qué la propia dinámica de los intercambios políticos entre la nación y las provincias, reproduce la desigualdad interprovincial que, por otra parte, ya era notoria al momento de la organización política del país.

del PBI) en http://www.asap.org.ar/informes-fiscales/ estadisticas-fiscales/

41 Véase también, Suárez (2011).

42 Fondos de distribución discrecional o inversión pública nacional. 


\section{Conclusión}

El federalismo argentino es un sistema de decisión complejo que se caracteriza por una descentralización tanto en términos político-administrativos como fiscales. Si bien existen normas que diseñan el reparto de competencias entre las diferentes instancias de gobierno al interior de la estructura estatal federal, tal como se evidenció en la última parte de este trabajo, las relaciones de esas instancias no son simples, ni mucho menos lineales, debido a que la matriz de decisión federal está atravesada por la interacción de distintos factores que surgen del propio "territorio" y que exceden el plano formal o jurídico.

Las provincias argentinas conservan mucho del enorme poder de sus tiempos confederados, y del mismo modo, la autoridad presidencial preserva la investidura y las potestades que se le otorgaron en la segunda mitad del siglo XIX, desempeñando un papel relevante y excluyente en la vida y quehacer nacional. Argentina se convierte así en un caso en que los fuertes sistemas presidencialistas y las instituciones federales no son mutuamente excluyentes sino que, por el contrario, coexisten.

En el ámbito de las políticas públicas, pensando en reformas deseables y factibles, y dada la dificultad de sancionar la ley-convenio de coparticipación federal de impuestos conforme manda la Constitución, podría aspirarse a que los regímenes fiscales complementarios que de seguro se seguirán aprobando, incluyan criterios de distribución interprovincial con claros objetivos progresivos y controles sobre la asignación geográfica de la inversión del gobierno nacional consistentes con las pautas de objetividad, equidad y solidaridad en el reparto consagradas en la Constitución Nacional, y con el tan mentado principio de subsidiariedad. El esquema federal fue la opción de quienes imaginaron y armaron el país y son quienes administran en la actualidad la nación los que deberán asumir los desafíos de perfeccionamiento que el sistema tiene por delante.

\section{Referencias}

Artana, D., Cristini, M., Moskovits, C., Bermúdez, G. \& Focanti, D. (2010). Argentina, política fiscal y cohesión social: el federalismo cuenta. Avances de Investigación, 39. Madrid: Fundación Carolina, CeALCI. Disponible en: http://www.fundacioncarolina.es/wp-content/ uploads/2014/07/Avance_Investigacion_39.pdf

Asensio, M. A. (2012). Desequilibrios territoriales y disparidades regionales en un contexto federal. Cuaderno de Federalismo, 25(1), pp. 171-183. Disponible en: http://bicentenario.unc.edu.ar/ acaderc/cuaderno-de-federalismo-xxv

Bazán, V. (2013). El federalismo argentino: situación actual, cuestiones conflictivas y perspectivas. Estudios Constitucionales, 11(1), pp. 37-88.

Bidart Campos, G. (2006). Manual de la Constitución reformada. Tomo 1. Buenos Aires: Ediar.

Boisier, S. (2004). Desarrollo territorial y descentralización. El desarrollo en el lugar y en las manos de la gente. Revista Eure, 30(90), pp. 27-40.

Chiaramonte, J. C. (1993). El federalismo argentino en la primera mitad del siglo XIX. En: Carmagnani, M. (coord.). Federalismos latinoamericanos: México/Brasil/Argentina (pp. 81-132). México D. F.: Fondo de Cultura Económica.

Dalla Via, A. (2011). El federalismo económico. En: Asensio, M. A. \& Garat, P. M. (coords.). Federalismo fiscal. Experiencia nacional y comparada (pp. 55-76). Buenos Aires: Rubinzal Culzoni.

De Riz, L. (2008). Reflexiones sobre el federalismo argentino. Revista Aportes, 26(1), pp. 115-120. Disponible en: http://www.asociacionag.org.ar/ pdfaportes/26/08.pdf

Falleti, T., González, L. \& Lardone, M. (eds.). (2013). El federalismo argentino en perspectiva comparada. Buenos Aires: Educa. 
Farah, P., Granato, L. \& Oddone, N. (2010). El desafío de la regionalización. Una herramienta para el desarrollo. Buenos Aires: Capital Intelectual.

Gelli, M. A. (2011). El federalismo en emergencia y su necesaria reconstrucción. En: Hernández, A. M. (dir.). Aspectos jurídicos e institucionales del federalismo argentino (pp. 10-28). Córdoba: Academia Nacional de Derecho y Ciencias Sociales.

Granato, L. \& Oddone, N. (2006). Globalización, servicios públicos y derecho de los usuarios. Prismas: Direito, Políticas Públicas e Mundialização, 3(2), pp. 278-287.

Hernández, A. M. (2008). Los aspectos financieros y económicos del federalismo argentino. En: Hernández, A. M. (dir.). Aspectos fiscales y económicos del federalismo argentino (pp. 11-43). Córdoba: Academia Nacional de Derecho y Ciencias Sociales.

Hernández, A. M. (2010). Aspectos históricos y políticos del federalismo argentino. En: Hernández, A. M. (dir.). Aspectos jurídicos $e$ institucionales del federalismo argentino (pp. 11-79). Córdoba: Academia Nacional de Derecho y Ciencias Sociales.

Leiras, M. (2013). Las contradicciones aparentes del federalismo argentino y sus consecuencias políticas y sociales. En: Acuña, C. H. (comp.). ¿Cuánto importan las instituciones? Gobierno,
Estado y actores en la política argentina (pp. 209-248). Buenos Aires: Siglo Veintiuno Editores.

Lijphart, A. (2000). Modelos de democracia. Formas de gobierno y resultados en treinta y seis países. Barcelona: Ariel.

Martiré, E. (2010). El federalismo en la República Argentina. En: Hernández, A. M. (dir.). Aspectos jurídicos e institucionales del federalismo argentino (pp. 103-120). Córdoba: Academia Nacional de Derecho y Ciencias Sociales.

Rodden, J. (2005). Federalismo e descentralização em perspectiva comparada: sobre significados e medidas. Revista de Sociologia e Política, 24(1), pp. 9-27.

Sabsay, D. A. (1999). El federalismo argentino. Reflexiones luego de la reforma constitucional. En: Agulla, J. C. (comp.). Ciencias sociales: presencia y continuidades (pp. 425-438). Buenos Aires: Academia Nacional de Ciencias.

Saguir, J. (2007). ¿Unión o secesión? Los procesos constituyentes en Estados Unidos (17761787) y Argentina (1810-1862). Buenos Aires: Prometeo.

Suárez, J. (2011). ¿ ¿Federal en teoría pero unitaria en la práctica? Una discusión sobre el federalismo y la provincialización de la política en Argentina. Revista SAAP, 5(2), pp. 305-321. Disponible en: http://www.saap.org.ar/esp/docs-revista/revista/ pdf/5-2/Suarez_Cao.pdf 